\title{
Third-hand smoke and children
}

\author{
Sri Lanka Journal of Child Health, 2011; 40(3): 87-89
}

(Key words: Third-hand smoke; children)

DOI: http://dx.doi.org/10.4038/sljch.v40i3.3505

First-hand smoke is that which is inhaled directly by the smoker. Second-hand smoke, otherwise known as environmental tobacco smoke (ETS), is a combination of mainstream smoke exhaled by the person smoking a cigarette and sidestream smoke which goes directly into the air from the end of a cigarette, pipe or cigar ${ }^{1}$. Second-hand smoke impairs a child's ability to learn and is neurotoxic even at extremely low levels ${ }^{2}$. Exposure to ETS increases both the number of ear infections a child will experience, and the duration of the illness ${ }^{3}$. Secondhand smoke is also associated with exacerbations of asthma in children ${ }^{4}$ and sudden infant death syndrome $(\mathrm{SIDS})^{5}$.

Third-hand smoke is the term used to describe the invisible toxic brew of gases and particles clinging to smokers' hair and clothing, cushions and carpeting which lingers on, long after second-hand smoke has cleared from a room. The term was coined by doctors from Massachusetts General Hospital for Children in Boston who defined "third-hand smoke" as the residual tobacco smoke contamination that remains after the cigarette is extinguished ${ }^{6}$. They reported on attitudes toward smoking in 1,500 households across the United States in a national random-digit-dial telephone survey done between September and November 2005. The study was designed to assess the health beliefs of adults regarding children exposed to third-hand smoke and whether such beliefs were associated with household smoking bans. Around $95 \%$ of nonsmokers and $84 \%$ of smokers agreed with the statement that "inhaling smoke from a parent's cigarette can harm the health of infants and children". However, only $65 \%$ of nonsmokers and $43 \%$ of smokers agreed with the statement that "breathing air in a room today where people smoked yesterday can harm the health of infants and children", which the researchers interpreted as acknowledgement of the risks of third-hand smoke. The belief that secondhand smoke harms children's health was not independently associated with strict smoking bans in homes and cars. In contrast, the belief that third-hand smoke was harmful to the children's health was independently associated with rules prohibiting smoking in the home 6 .

San Diego State University researchers have found that cigarette smoke pollutants can attach to home surfaces and slip into crevices for long periods of time after the smoker has already moved out ${ }^{7}$. Despite the fact that the home has been vacant for months and even cleaned after a smoker has left, the third-hand smoke remains and can affect a new non-smoking occupant ${ }^{7}$.

The burning of tobacco releases nicotine in the form of a vapour that adsorbs strongly on to indoor surfaces, such as walls, floors, carpeting, drapes and furniture. Nicotine can persist on those materials for days, weeks and even months ${ }^{8}$. A multi-institutional study led by researchers with the Lawrence Berkeley National Laboratory showed that when this residual nicotine reacts with nitrous acid, an indoor pollutant commonly found in homes with gas-burning appliances, it forms carcinogenic tobacco-specific nitrosamines (TSNAs). They used cellulose as a model of indoor material, exposed it to cigarette smoke and then exposed it to a "high but reasonable" concentration of nitrous acid for three hours. The levels of newly formed TSNAs were 10 times higher after the nitrous acid exposure ${ }^{8}$. The researchers suggest various ways to limit the impact of the third hand smoke health hazard, including implementation of $100 \%$ smoke-free environments in public places and self-restrictions in residences and automobiles. Using fans and opening a window does not help eliminate the hazards because most of the nicotine and other substances from burning cigarettes are not found in the air, but are absorbed by surfaces. In buildings where substantial smoking has occurred, replacing nicotine-laden furnishings, carpets and wallboard can significantly reduce exposures ${ }^{8}$. Whilst smoking outside is better than smoking indoors, the nicotine residues will stick to a smoker's skin and clothing, follow a smoker back inside and get spread everywhere. The biggest risk is to young children. Dermal uptake of the nicotine through a child's skin is likely to occur when the smoker returns and if nitrous acid is in the air, TSNAs will be formed ${ }^{8}$.

A new study shows that third-hand smoke, the nicotine residue that is left behind on furniture, walls and carpeting after a cigarette has been smoked in a room, can become airborne a second time ${ }^{9}$. The resulting particulates, a toxic mixture of ozone and nicotine, are so small that they can easily penetrate into the deepest parts of the lung, and over time, could contribute to breathing problems like asthma or even cancer. Furthermore, because ozone can continue to pull 
nicotine off surfaces and back into the air for months, exposure to third-hand smoke may continue long after smoking in the area has ceased ${ }^{9}$.

Infants and children are especially at risk of third-hand smoke through contact with surfaces and dust contaminated with residual smoke gases and particles ${ }^{7}$. Children pick up the residue from dust when crawling, and then may ingest it by sucking on their hands. Infants are smaller and have faster breathing rates and hence are exposed to higher concentrations than older children. Infants and children are particularly vulnerable to the toxins found in third-hand smoke for the following reasons $^{6}$ :

- Children ingest twice the amount of dust particles as adults.

- Infants and children explore objects with their mouths.

- Brains in the process of development are more susceptible to even the lowest level of toxins.

What can adults do to protect children from the dangers of third-hand smoke? The best way is, of course, complete abstinence from cigarettes. Enforcing strict, no-smoking policies in the home may help to a certain degree, but toxins still remain on clothing. If you continue to smoke, the best thing to do is to smoke outside of your home (and not in your car), and, before coming into contact with infants or children, be sure to wash your hands and change your clothes. Further, delaying contact with children for up to five minutes after your last cigarette is beneficial since tobacco residuals stay in the lungs of a smoker after he or she takes the very last puff of a cigarette and it can then take a few minutes before the smoker stops exhaling the toxic products of combustion that had been trapped in his or her lungs.

While the above studies point to a new tobacco hazard from third-hand smoke, more research is needed to ascertain whether the noxious remnants of extinguished cigarettes actually cause disease and kill like first- and secondhand smoke.

\section{References}

1. Lucas GN. Passive smoking in infants and children. Sri Lanka Journal of Child Health 2007; 36: 81-3.

2. Yolton K, Dietrich K, Auinger P, Lanphear BP, Hornung R. Exposure to environmental tobacco smoke and cognitive abilities among U.S. children and adolescents. Environmental Health Perspectives 2005; 113(1):98-103.
3. Etzel RA, Pattishall EN, Haley NJ, Fletcher RH,Henderson FW. Passive smoking and middle ear effusion among children in Day Care. Pediatrics 1992; 90(2): 228-32.

4. Chilmonczyk BA, Salmun LM, Megathlin KN, Neveux LM, Palomaki GE, Knight GJ, et al. Association between exposure to environmental tobacco smoke and exacerbations of asthma in children. $N$ Engl $J$ Med 1993; 328:1665-9. http://dx.doi.org/10.1056/NEJM199306103282303

5. Mitchell EA, Ford RP, Stewart AW, Taylor BJ, Becroft DM, Thompson JM, et al. Smoking and the sudden infant death syndrome. Pediatrics 1993; 91:893-6.

6. Winickoff JP, Friebely J, Tanski SE, Sherrod C, Matt GE, Hovell MF, et al. Beliefs about the health effects of "third-hand" smoke and home smoking bans. Pediatrics 2009: 123(1):e74-9.

7. Matt GE, Quintana PJ, Hovell MF, Bernert JT, Song S, Novianti N, et al. Households contaminated by environmental tobacco smoke: sources of infant exposures. Tob Control. 2004; 13(1):29-37. http://dx.doi.org/10.1136/tc.2003.003889

8. Sleiman M, Gundel LA, Pankow JF, Jacob P, Singer BC, Destaillats H. Formation of carcinogens indoors by surface-mediated reactions of nicotine with nitrous acid, leading to potential third-hand smoke hazards. Proceedings of the National Academy of Sciences 2010; 107(15): 6576-81. http://dx.doi.org/10.1073/pnas.0912820107

9. Petrick LM, Svidovsky A, Dubowski Y. Thirdhand smoke: Heterogeneous oxidation of nicotine and secondary aerosol formation in the indoor environment. Environmental Science \& Technology 2011; 45 (1): 328. http://dx.doi.org/10.1021/es102060v

\section{G N Lucas}

Joint Editor 